\title{
Research on Roller Straightening Process for Stainless Steel Clad Plate
}

\author{
Herong Jin ${ }^{1,2, a}$, Xukun Yang ${ }^{3, b}$ and Xueyan $\operatorname{Han}^{3, c}$ \\ ${ }^{1}$ Key Laboratory of Advanced Forging \& Stamping Technology and Science of Ministry of National \\ Education, Yanshan University, Qinhuangdao, 066004, China; \\ ${ }^{2}$ Parallel Robot and Mechatronic System Laboratory of Hebei Province, Yanshan University, \\ Qinhuangdao, 066004, China; \\ ${ }^{3}$ School of Mechanical Engineering, Yanshan University, Qinhuangdao, 066004, China. \\ aysujhr@ysu.edu.cn, byiyali@ysu.edu.cn, chanxueyan@ysu.edu.cn
}

Keywords: Stainless steel clad plate, straightening process, FEA.

\begin{abstract}
In order to achieve the shape finishing and stress reforming of wide stainless steel clad plate after rolling, based on the elasto-plastic straightening theory, combined with the 11-roller straightening scheme, the isothermal residual curvature straightening process is presented. The straightening process model is established using the FEA software, analyzing the influence of straightening velocity on the plainness and residual stress. The results show that the finishing plainness is acceptable after straightening. Residual stress adjustment of plate after rolling can be realized, that provides previous theory basis for the application of stainless steel clad plate technology.
\end{abstract}

\section{Introduction}

Stainless steel clad plate is a new complex which is made of carbon or low-alloy steel (the base) and stainless steel (the cladding), it has both the strength and rigidity of base material, but also the corrosion resistance, heat resistance, wear resistance of cladding material. The clad plate can save $70 \%-80 \%$ of $\mathrm{Cr}$, $\mathrm{Ni}$ and other alloying elements, and save a lot of stainless steel, so it is suitable for aggressive serious industrial or marine atmosphere[1,2].Because of the deformation resistance and thermal expansion coefficient of stainless steel cladding plate and steel substrate is different, the hot-rolled stainless steel clad plate appear great bending deformation and residual stress to the side of cladding plate after rolling , this defect is difficult to eliminate in the cold state and greatly influenced the shape quality[3].

Parallel roller leveler can straighten plate with different original curvature by many times of repeated bending, reduce the residual stress and make it homogenization[4]. In the roller straightening process, a suitable intermesh is the key of ensuring the quality of straightening. At present, a lot of researches have been done about bending deflection model and reduction pattern on roller straightening of plate[5].With the development of finite element theory, simulating the plate straightening process by the finite element analysis software can accurately forecast the law of straightening[6]. However, in many reports, the research of stainless steel clad plate straightening technology is rare. In this paper, for the problem of hot-rolled stainless steel clad plate straightening, based on the elasto-plastic straightening theory, the isothermal residual curvature straightening process is given. Using explicit dynamic finite element analysis software ANSYS / LS-DYNA to simulate roller-straightening process and analyze the effect of straightening process parameters on straightening quality, which provide some guidance for the production practices of stainless steel clad plate.

\section{Straightening process scheme}

The temperature of hot-straightening is generally between $500^{\circ} \mathrm{C}$ and $800{ }^{\circ} \mathrm{C}$, at the same temperature, thermal expansion coefficient of stainless steel cladding plate $\boldsymbol{\alpha}_{\mathbf{1}}$ is greater than that of 
carbon steel substrate $\boldsymbol{\alpha}_{\mathbf{2}}$. As a result, in the cooling process, the contraction length of stainless steel cladding plate is larger than that of the carbon steel substrate, resulting in longitudinal bending to the side of cladding plate. In view of this phenomenon, isothermal residual curvature straightening process plan is made, that is, in the hot-straightening process, keeping the temperature of two base metals of stainless steel clad plate consistent, at the end of the straightening progress, the stainless steel clad plate have some residual curvature bending to a substrate side. When the temperature decreases to the room temperature, the difference of thermal expansion coefficient of the two base metal make the clad plate into the straight state.Using 11 rolls medium and heavy plate leveler conduct bending calculation, as shown in Fig. 1.

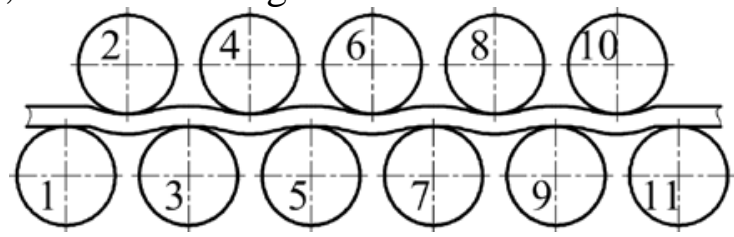

Fig. 1 Structure diagram of roller straightening model

When setting the intermesh of straightening roller, the intermesh of the first four straightening rollers adopt small deformation straightening scheme to make the stainless steel clad plate flat, and the last intermesh give the stainless steel clad plate a residual curvature for bending to the side of the cladding plate. The intermeshes of straightening roller are obtained as shown in Table 1.

Table 1 Reduction of each roller in mm

\begin{tabular}{ccc}
\hline Roll No. & $\begin{array}{c}\text { Initial curvature } 0.1 \mathrm{~m}^{-1} \\
\text { the intermesh }\end{array}$ & $\begin{array}{c}\text { Initial curvature } 0.2 \mathrm{~m}^{-1} \\
\text { the intermesh }\end{array}$ \\
\hline 2 & 0.22 & 0.24 \\
4 & 0.186 & 0.189 \\
6 & 0.176 & 0.178 \\
8 & 0.172 & 0.175 \\
10 & 0.21 & 0.22 \\
\hline
\end{tabular}

\section{Finite element model}

Taking the above-mentioned analysis data as the simulation object, establish the finite element model of roller straightening, as shown in Fig.2. Straightening temperature is $600^{\circ} \mathrm{C}$. Considering the role of the backup roll, the straightening roll is taken as a hollow rigid body. Eight nodes solid element is used to establish the bilinear kinematic hardening material model. Due to the special nature of the joint surface of clad plate, using Glue Boolean operations for the joint surface of substrate and cladding plate before meshing, ensure the joint surface sharing the nodes. Modeling using 1/2 of the plate width, unit is divided into $165 \times 50 \times(7$ base plates+3cladding plates) (Length $\times$ width $\times$ thickness ),82,500 in all.

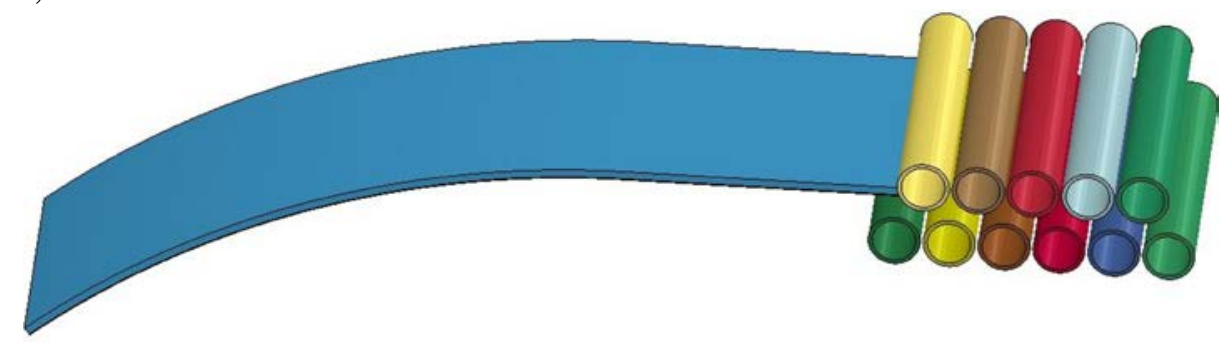

Fig.2 FEM straightening model

As can be seen from Table 2, after straightening, stainless steel clad plate bent to the substrate side, coinciding with the results of the process. With the increasing of straightening speed or the original curvature, elastic-plastic deformation rate of stainless steel clad plate increases, material work hardening phenomenon is more obvious, resulting in the simulation required intermesh greater than the theoretical amount. The value of residual curvature radius increases, and has a certain bias comparing with the theoretical calculation $89 \mathrm{~mm}$. Through calculation, the maximum roughness after 
straightening is $1.53 \mathrm{~mm} / \mathrm{m}$, the smallest roughness is $0.64 \mathrm{~mm} / \mathrm{m}$. According to residual curvature straightening process with the temperature difference, along with the cooling after straightening, stainless steel clad plate will generate shrinkage deformation to the side of cladding plate, the roughness values will be further improved.

Table 2 Residual curvature radius after straightening

\begin{tabular}{cccc}
\hline $\begin{array}{c}\text { Straightening } \\
\text { speed }(\mathrm{m} / \mathrm{s})\end{array}$ & $\begin{array}{c}\text { Original curvature } \\
(1 / \mathrm{m})\end{array}$ & $\begin{array}{c}\text { Simulation residual } \\
\text { curvature radius }(\mathrm{m})\end{array}$ & $\begin{array}{c}\text { Theoretical residual } \\
\text { curvature radius }(\mathrm{m})\end{array}$ \\
\hline \multirow{2}{*}{0.5} & -0.1 & 81.87 & \\
& -0.2 & 88.28 & 89 \\
1 & -0.1 & 113.285 & \\
\multirow{2}{*}{1.5} & -0.2 & 134.81 & \\
& -0.1 & 190.58 & \\
\hline
\end{tabular}

\section{The impact of straightening speed on residual stress after straightening}

The effect of straightening speed on straightening quality has no theoretical calculation method so far, but the experience of artificial setting straightening speed can be followed. The Analysis of the longitudinal residual stress of stainless steel clad plate after straightening under three different straightening speed, shown in Fig.3, Fig.4 and Fig.5.

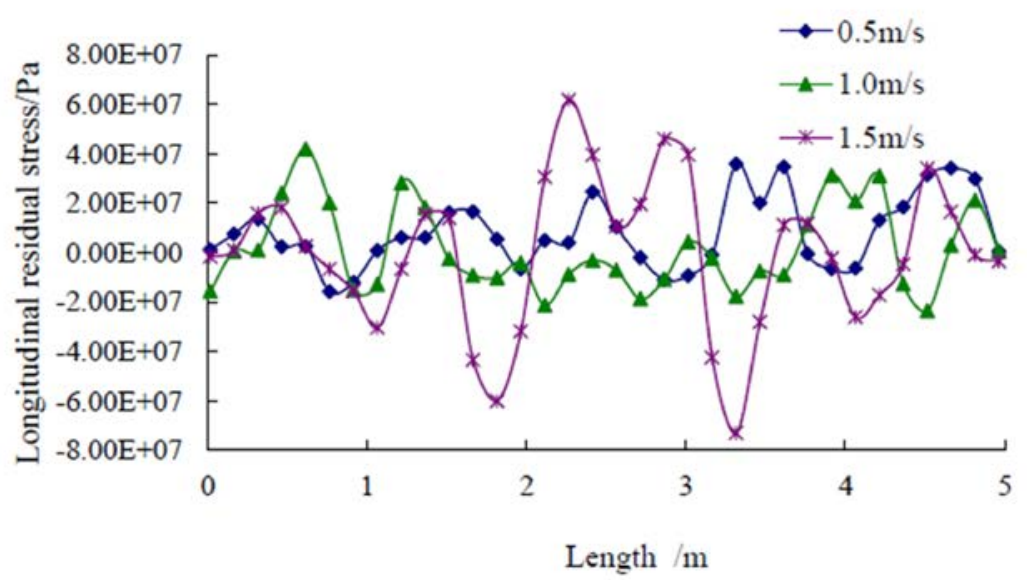

Fig. 3 Longitudinal residual stress on the base surface path across length with different velocity

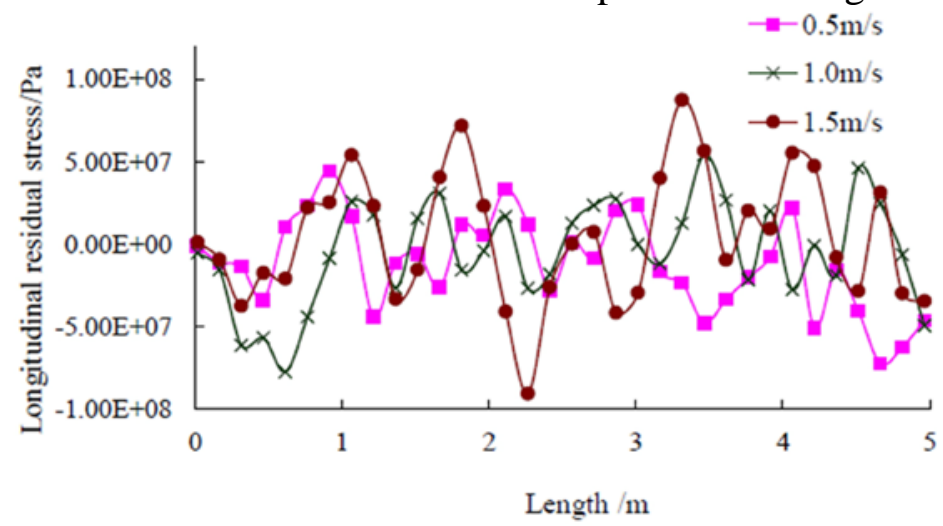

Fig. 4 Longitudinal residual stress on the clad surface path across length with different velocity

Fig. 3 and Fig.4 show that along the length direction, the longitudinal residual stress distribution of substrate surface is identical with that of the cladding plate surface. With the straightening speed increasing, residual stress peak increases. When the straightening speed is between $0.5 \mathrm{~m} / \mathrm{s}$ and $1 \mathrm{~m} / \mathrm{s}$, the change of peak value is not great. When the straightening speed is $1.5 \mathrm{~m} / \mathrm{s}$, the longitudinal residual stress waves sharply and the peak increases. The stress of substrate side reaches $68 \mathrm{MPa}$, and the stress of cladding side reaches $85 \mathrm{MPa}$, this is quite negative to the plate shape after straightening. 
Fig.5 shows that in the width direction, longitudinal residual stress distribution is basically identical, and straightening speed has no effect on the longitudinal residual stress distribution of stainless steel clad plate in the width direction.

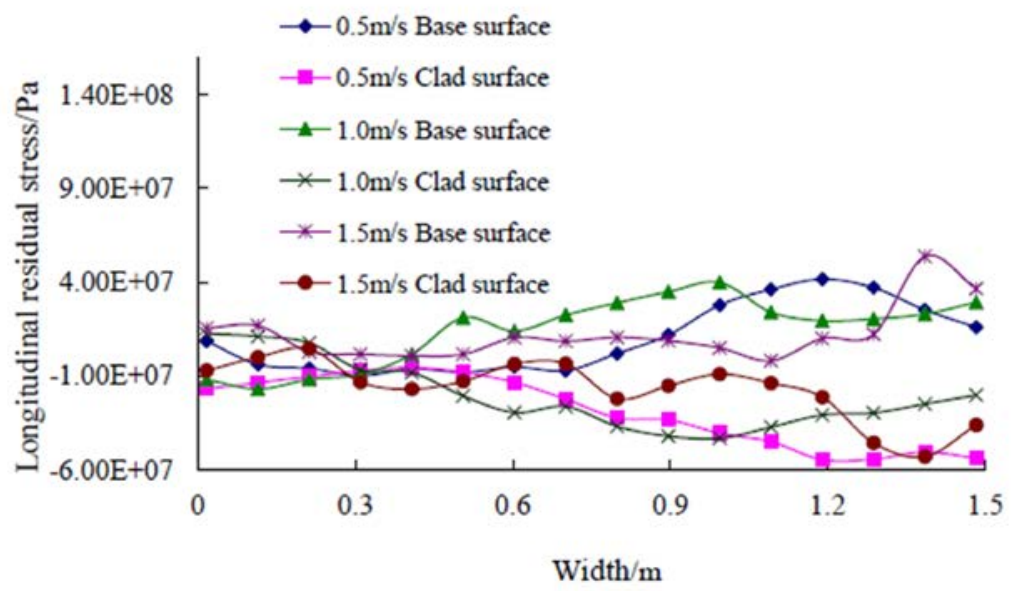

Fig. 5 Longitudinal residual stress on the surface path across width with different velocity

The above analysis shows that increasing the straightening speed appropriately can improve straightening efficiency while ensuring the straightening quality. However, a larger straightening speed will increase the deformation speed of the material, the surface cracks and joint surface peeling should be avoided.

\section{Summary}

A flat stainless steel clad plate at room temperature can be obtained through the program of the isothermal residual curvature straightening, and its roughness requirements can be guaranteed.By the finite element analysis of the straightening speed, the longitudinal residual stress distribution after straightening can be predicted and the process parameters can be set effectively, reducing the longitudinal residual stresses on the surface of stainless steel clad plate, obtaining excellent shape quality as well.

\section{Acknowledgements}

This material is based upon work supported by Natural Science Foundation of Steel and Iron Foundation of Hebei Province of China (grant no. E2014203118)

\section{References}

[1] M. N. Yang, X. Q. Zuo and M. W. Zhao, Research progress of manufacturing technology for stainless steel clad plate, Mater. \& Heat Treat. 3(2013)43-47.

[2] W. Yu, Y. M. Zhang and C. Y. He, et al. Production of heavy-gauge steel plates by clad rolling process, J.Univ.Sci.Technol.B.11(2011)1391-1395.

[3] Y. Y. Wang, Longitudinal buckle of asymmetric cladded stainless steel plates for hot rolling, J.Iron. Steel.Res.Int. 4(1993)17-23.

[4] E. Doege, R. Menz, S. Huinink, Analysis of the leveling process based upon an analytic forming model, Annals of the CIRP. 1(2002)191-194.

[5] F. Kosel, T. Videnic, and T.Kosel, Elasto plastic springback of beams subjected to repeated bending/unbending histories, J.Mater.Eng.Perform. 6(2011) 846-854.

[6] C. L. Zhou, G. D. Wang and X. H. Liu, The FEM analysis for the effect of intermesh to plate leveling deformation, J.Plast.Eng. 1(2006) 78-81. 